\title{
Analysis of Inclusions with Unqualified Z- direction Performance of Heavy Bridge Plates
}

\author{
Haihe Luo \\ Application Technology Institute \\ R \& D Center of Wuhan Iron and Steel (Group) Corp. \\ Wuhan, China \\ 13986055195@163.com
}

\author{
Zhanzeng Liu \\ Application Technology Institute \\ R \& D Center of Wuhan Iron and Steel (Group) Corp. \\ Wuhan, China \\ liuzz@wisco.com.cn
}

\begin{abstract}
By using the analysis tools of scanning electron microscope (SEM) and energy dispersive X-ray (EDX), the reason for the disqualified Z-direction performance of a $60 \mathrm{~mm}$ Q370qEZ35 heavy steel plate was investigated. The results showed that the disqualified Z-direction performance of Q370qEZ35 was due to the presence of a large number of inclusions, the types of which were mainly massive and striplike ( $\mathrm{Nb}, \mathrm{Ti}) \mathrm{C}$ and metal $\mathrm{Nb}$ inclusions as well as spherical oxide ( $\mathrm{MgO}, \mathrm{Al}_{2} \mathrm{O}_{3}$, etc.) and sulfide inclusions (CaS, $\mathrm{MnS}$ ). The cause of various types of inclusions and the impact on the Z-direction property was analyzed, and the corresponding improvement measures were put forward from smelting, casting and rolling and cooling process, such as controlling the amount and adding time of $\mathrm{Nb}$ and $\mathrm{Ti}$, extending the refining time, controlling the superheat temperature, optimizing the process of heating, rolling and cooling, etc., and finally, we achieved good results.
\end{abstract}

Keywords-Q370qEZ35; Heavy plate; Z-direction performance; Fracture morphology; Cause analysis

\section{INTRODUCTION}

With the increase in the level of design and construction of the bridges, the numbers of large-span bridges are gradually increasing; the connection types are developed from riveting and bolting to the whole welding [1-3]. Large-span steel bridges require not only high strength, high toughness, good weldability and seismic performance, but also good resistance to lamellar tearing performance, which is also named the thickness direction performance or the Z-direction performance [4-5]. The Zdirection steels are generally obtained by smelting, rolling and after heat treatment, which are based on some kind of structural steel (called the mother grade steel). They have lower sulfur content than ordinary steel, and the grade level of which can be divided into Z15, Z25 and Z35[6].

In this study, the Q370qEZ35 heavy steel plates were produced to meet the needs of bridge engineering. However, in the actual production process, we found the Z-direction performances of some batches of steel were lower, and they could not meet the technical delivery conditions. Therefore, in this paper, we intend to use

\author{
Hanxiong Dong \\ Structural Steel Institute \\ R \& D Center of Wuhan Iron and Steel (Group) Corp. \\ Wuhan, China \\ wgdhx@126.com \\ Fu Chen \\ Application Technology Institute \\ R \& D Center of Wuhan Iron and Steel (Group) Corp. \\ Wuhan, China \\ cf 0115@163.com
}

scanning electron microscopy (SEM) and energy dispersive X-ray (EDX) to analyze the microstructures and inclusion types of the plate, find out the reasons for unqualified Z-direction performance, and thus suggest improvement measure to increase the passing rate of $Z$ direction performance, and finally meet the supply needs.

\section{EXPERIMENTAL PROCEDURE}

\section{A. Experimental Materials}

According to GB/T 5313-2010 "Steel plates with through-thickness characteristics" and GB/T 228.1-2010 "Metallic materials-Tensile testing-Part 1: method of test at room temperature", the experimental materials were cut from the Q370qEZ35 defect plate, the thickness of which was $60 \mathrm{~mm}$, and its chemical compositions were listed in Table 1 .

TABLE I. THE CHEMICAL COMPOSITIONS OF THE TESTED MATERIALS (WT.\%)

\begin{tabular}{|c|c|c|c|c|c|c|}
\hline $\mathbf{C}$ & Si & Mn & P & S & Nb & Als \\
\hline$\leq 0.18$ & $\leq 0.55$ & $1.0 \sim 1.70$ & $\leq 0.020$ & $\leq 0.010$ & $\leq 0.060$ & $\geq 0.015$ \\
\hline
\end{tabular}

The actual rolling process and Z-direction performance of the heavy plate was shown in Table 2 and Table 3.

TABle II. Rolling Processes of The Plate

\begin{tabular}{|c|c|c|c|c|c|}
\hline \multicolumn{2}{|c|}{ Stage I } & \multicolumn{3}{|c|}{ Stage II } & \multirow[b]{2}{*}{$\begin{array}{c}\text { Finishing } \\
\text { cooling } \\
\text { Temp. } \\
{ }^{\circ} \mathrm{C}\end{array}$} \\
\hline $\begin{array}{c}\text { Open } \\
\text { rolling } \\
\text { Temp. } \\
\quad /{ }^{\circ} \mathrm{C}\end{array}$ & $\begin{array}{l}\text { Finishing } \\
\text { rolling } \\
\text { Temp. } \\
\quad /{ }^{\circ} \mathrm{C}\end{array}$ & $\begin{array}{c}\text { Open } \\
\text { rolling } \\
\text { Temp. } \\
/{ }^{\circ} \mathrm{C}\end{array}$ & $\begin{array}{l}\text { Finishing } \\
\text { rolling } \\
\text { Temp. } \\
\quad /{ }^{\circ} \mathrm{C}\end{array}$ & $\begin{array}{c}\text { Intermediate } \\
\text { slab } \\
\text { thichness } \\
\text { /mm }\end{array}$ & \\
\hline$\geq 1150$ & $\geq 1000$ & $\leq 950$ & $\geq 850$ & $100 \sim 120$ & $650 \sim 750$ \\
\hline
\end{tabular}

TABle III. Z-Direction Performance of The Plate

\begin{tabular}{|c|c|c|c|c|}
\hline \multirow{2}{*}{$\begin{array}{c}\text { Thickness } \\
\text { /mm }\end{array}$} & \multicolumn{4}{|c|}{ Z-direction performance } \\
\cline { 2 - 5 } & $\mathbf{Z 1}$ & $\mathbf{Z 2}$ & $\mathbf{Z 3}$ & Average \\
\hline 60 & 21.5 & 18.5 & 17.0 & 19.0 \\
\hline
\end{tabular}




\section{B. Characterization}

The fracture morphologies and the inclusion types of the tested specimens were investigated by using SEM (FEI Quanta 400) and EDX.

\section{RESUltS AND DisCUSSION}

\section{A. Tensile Fracture Morphologies Analysis}

According to the SEM analysis, the fracture morphologies of Z1, Z2 and Z3 were similar. Therefore, we chose the $\mathrm{Z} 3$ as a representative specimen for analysis. The tensile fracture morphologies were shown in Figure 1.
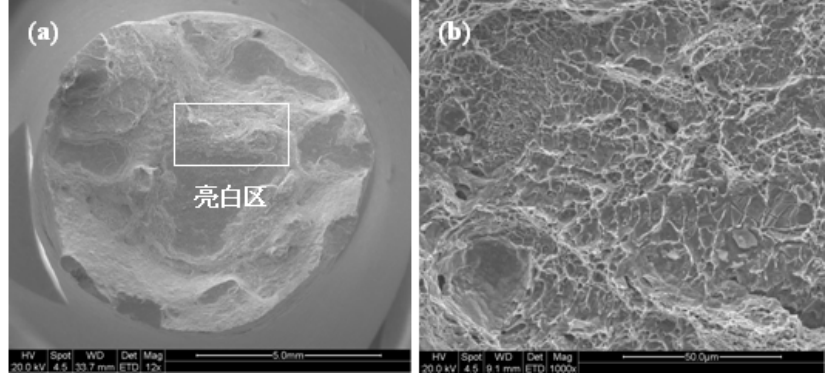

Figure 1. Tensile fracture morphologies of the tested specimens

From Figure 1, it can be seen that the tensile fracture had typical ductile fracture morphology, the surface was irregularities (fibrous) and distributed different sizes of dimples (Figure 1b), and there existed of inclined sections at the edge of the fracture (shear lip morphology). Most areas of the fracture were showing dark gray, but there were bright white regions in some areas, the fracture of these regions were relatively smooth, and there were presence of significant particulate matters.

\section{B. Inclusions Analysis}

In order to investigate the type of the particulate matters in the bright white region, one region was enlarged and the composition of the particles was analyzed, the results were shown in Figure 2.

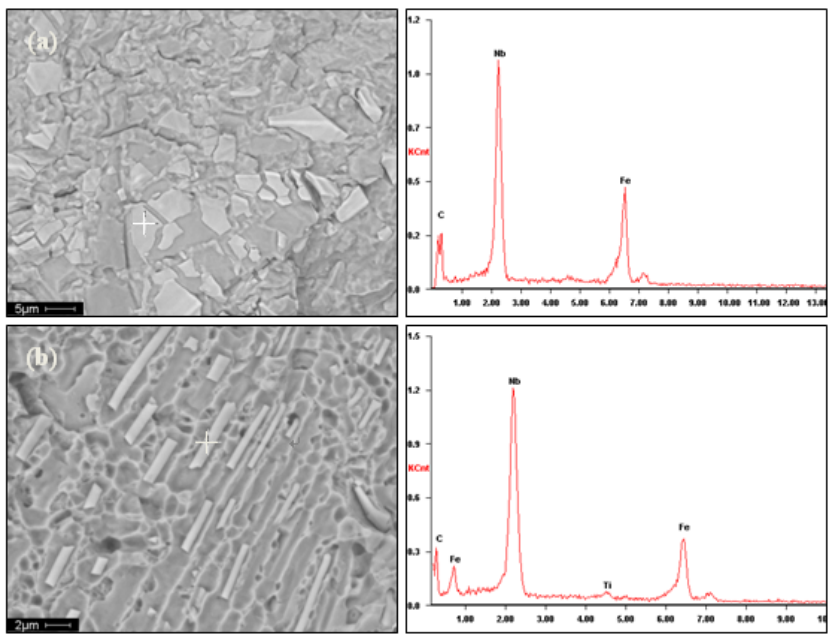

Figure 2. EDX analysis of the inclusions

As shown in Figure 2, it can be found that there were many massive and strip-like inclusions, which distributed densely together, the main chemical compositions, were
$\mathrm{Nb}$, Ti and $\mathrm{C}$. The dimensions of the inclusions were from less than 1 micron to more than ten microns, the total length was up to hundreds of microns.

In addition to the above inclusions, some spherical inclusions were also be found in tough nest, whose sizes were generally about several microns, the chemical compositions of which were mainly $\mathrm{O}, \mathrm{Mg}, \mathrm{Al}, \mathrm{S}, \mathrm{Ca}, \mathrm{Mn}$, $\mathrm{Fe}$, and also a small number of $\mathrm{Na}$ and $\mathrm{Si}$ (see Figure.3a), They might be formed the simple compounds $\mathrm{MgO}, \mathrm{Al}_{2} \mathrm{O}_{3}$, $\mathrm{CaO}, \mathrm{SiO}_{2}, \mathrm{CaS}, \mathrm{MnS}, \mathrm{FeS}$, etc., or some complex compounds. In addition, there were large pieces of $\mathrm{MnS}$ inclusions, as shown in Figure $3 \mathrm{~b}$.

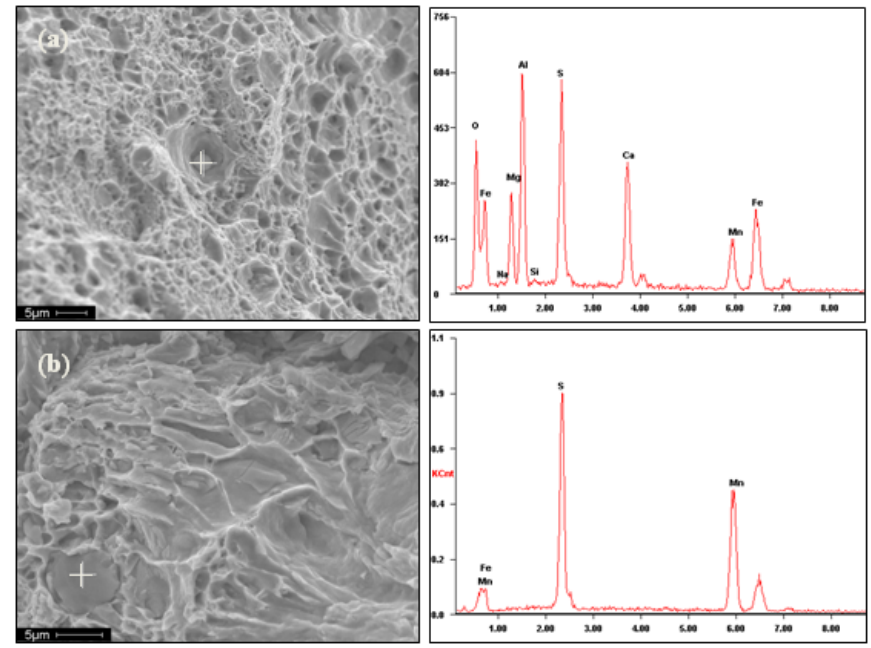

Figure 3. EDX analysis of the inclusions

\section{Discussion}

From the EDX anlysis results in Figure 2, it can be obseved that the main elements of the inclusions were $\mathrm{C}$, $\mathrm{Nb}$ and $\mathrm{Ti}$, and therefore it can be inferred that they mihgt be present in the form of $(\mathrm{Nb}, \mathrm{Ti}) \mathrm{C}$. According to some researches [7-8], in the solidification process, at the beginning, the $\mathrm{C}, \mathrm{Nb}$ and $\mathrm{Ti}$ contents of some liquid steel were less than the average content, and in the solidification front, these three elements progressively enriched, when the sodificaiton reached to a certain stage, due to the increased $\mathrm{C}, \mathrm{Nb}$ and $\mathrm{Ti}$ contents, the concentration of the compound $\mathrm{C}-\mathrm{Nb}$ and $\mathrm{C}-\mathrm{Ti}$ was reached, so the $\mathrm{C}-\mathrm{Nb}$ and $\mathrm{C}-\mathrm{Ti}$ inclusions will be formed in the solidification microstructure. The presence of a large number of $\mathrm{C}-\mathrm{Nb}$ and $\mathrm{C}-\mathrm{Ti}$ inclusions, undermined the strength and toughness of the Z-direction, resulted in the cracking along the $\mathrm{Nb}-\mathrm{Ti}$ particle distribution layers when the heavy plate subjected to a large tensile stress. In addition, from Figure 2, it also found that the inclusions mostly presented in the form of blocky and rod, which had large sizes, quantities, and the relatively higher content of $\mathrm{Nb}$, that indicated metal $\mathrm{Nb}$ will be presented. In the design of the steel's composition, $\mathrm{Nb}$ was an important component elements, whcih was mainly obtained through adding niobium alloy, the niobium alloy had a high melting point $\left(1580 \sim 1630{ }^{\circ} \mathrm{C}\right)$ and density $\left(8.1 \mathrm{~g} / \mathrm{cm}^{3}\right)$, it was insoluble in the liquid steel, mainly dissolved by $[\mathrm{Nb}]$ diffusion[9]. If the niobium alloy was too small, it will be lost in the form of dust or be captured in the slag; but if that was too large, niobium, it will be quickly sinking and 
accumulating in the bottom of the ladle when added to the molten steel, part of the $[\mathrm{Nb}]$ wil be diffused and dissolved, and the others will be enriched into the central portion of the slab in the continuous casting process, and finally be presented in the continuous casting in the form of metal niobiums[10]. In the subsequent rolling process, due to the limited rolling force and compression ratio, the large pieces of metal niobiums were difficult to be broken, an then existed obtain in the form of large-sized inclusions in the heavy plate. As can be seen from Figure 3, there were a small amount of oxide and sulfide inclusions dispersed in the tensile fracture, such as $\mathrm{MgO}, \mathrm{Al}_{2} \mathrm{O}_{3}$, $\mathrm{CaO}, \mathrm{SiO}_{2}$ and $\mathrm{CaS}, \mathrm{MnS}, \mathrm{FeS}$ and so on. The oxide inclusions were generally brittle inclusios, which will be broken at a sufficient rolling force, but the inclusions as shown in Figure 3 (a) embedded in the dimples of the tensile fracture, it is difficult to get broken. However, the sulfide inclusions wer generally plastic inclusions, which were the product of precipitates when the sulfur in the molten steel solidificated, they were not be broken or deformed in the rolling process. Therefore, the above composite inclusions also impacted the Z-direction performance of the heavy plate.

In summary, the presence of inclusions was the main cause of the unqualified Z-direction performance of the Q370qEZ35 heavey plate. A large number of $(\mathrm{Nb}, \mathrm{Ti}) \mathrm{C}$ and metal $\mathrm{Nb}$ inclusions were accumulatively distributed in steel core, formed the inclusion bands with dozens or even hundreds of microns, destroyed the continuity of the steel substrate, resulted in the uniformity of the microstructure. Due to presenting a large number of hard and brittle microstructure, and thus in the Z-direction tensile stress, the cracking will be formed on the contact surface of the steel substrate and the inclusions, and then continue to expand along the extension direction of the inclusions, and eventually connected to each other through, caused the Z-direction performances of the steel plate dramaticly being destroyed. In addition, although the sulfide inclusions were the plastic inclusions, but when the steel subjected to Z-direction stress, they will have a greater concentration of stress at the end of the inclusions, and thus induced the microcracks and finally reulted in the the destruction of the Z-direction tensile property of the steel plate.

\section{IMPROVEMENT}

\section{A. Smelting Process Control}

In the smelting process, in order to improve the slab quality and reduce the formation of large particles of $\mathrm{Nb}$ and Ti compounds, some measures were implemented, such as reducing appropriately the internal target of $\mathrm{Nb}$, optimizing the slagging process, and strictly controlling the added time, tapping temperature and the tapping time of $\mathrm{Nb}$ alloys and $\mathrm{Ti}$ alloys. In addition, strengthening the control of the refining process, extending the refining time for $5 \sim 10 \mathrm{mim}$, to make the white slags fully maintained. Moreover, optimizing the process of argon blowing, the argon blowing time will be prolonged for $5 \sim 8 \mathrm{~min}$, to make the inclusions fully floating up.

\section{B. Casting Process control}

Applying the low-temperature fast pouring process, meanwhile, reducing the superheat of the molten steel, and controlling the superheat of which in less than $25^{\circ} \mathrm{C}$. Furthermore, improving the solidification rate of the slab, supported by a stable casting speed, in order to effectively reduce the excessive growth of $\mathrm{Nb}$ and $\mathrm{Ti}$ carbonitride precipitates and the generation of the large-size inclusions

\section{Rolling and Cooling Process Control}

Optimizing the slab heating process, the temperature of the soaking zone was increased $20 \sim 30{ }^{\circ} \mathrm{C}$, the heating time was prolonged for $20 \mathrm{~min}$. In the controlled rolling stage, applying the high-temperature high-reduction process, rolling pass reduction of the two roll was greater than $20 \mathrm{~mm}$, the cumulative reduction ratio was greater than $60 \%$, of which the cumulative reduction ratio of the last three passes was greater than $30 \%$, so that the grains in the slab core were fully broken. The finishing temperature will be controlled between $820^{\circ} \mathrm{C}$ and $840^{\circ} \mathrm{C}$, and then by optimizing the upper and lower water ratio of the ACC system, the final cooling temperature was controlled below $650{ }^{\circ} \mathrm{C}$, and then cooling slowly on the cooling bed, in order to fully refine the grains, meanwhile reduce the microstructural defects and improve the comprehensive performances of the plate.

\section{IMPROVED RESULTS}

After the above improved processes had been completed, four heavy plates were produced, of which there were two $60 \mathrm{~mm}$ and two $64 \mathrm{~mm}$, their mechanical properties were shown in Table 4.

TABle IV. The Mechannical Properties of The Plate

\begin{tabular}{|c|c|c|c|c|c|c|c|c|c|c|}
\hline \multirow[t]{2}{*}{$\begin{array}{l}\text { Thk. } \\
\text { /mm }\end{array}$} & \multirow[t]{2}{*}{$\begin{array}{c}\mathbf{R}_{\mathrm{eL}} \\
/ \mathbf{M P a}\end{array}$} & \multirow[t]{2}{*}{$\begin{array}{c}\mathbf{R}_{\mathbf{m}} \\
/ \mathbf{M P a}\end{array}$} & \multirow[t]{2}{*}{$\begin{array}{c}\mathrm{A} \\
1 \%\end{array}$} & \multicolumn{3}{|c|}{$\begin{array}{c}-40^{\circ} \mathrm{CA} A_{\mathrm{kv} 2} \\
/ \mathrm{J}\end{array}$} & \multicolumn{4}{|c|}{$\begin{array}{c}\text { Z-direction Performances } \\
/ \%\end{array}$} \\
\hline & & & & & & & Z1 & Z2 & Z3 & Avg. \\
\hline 60 & 420 & 565 & 30 & 216 & 209 & 223 & 54.5 & 52.3 & 55.8 & 54.2 \\
\hline 60 & 430 & 570 & 29 & 190 & 187 & 196 & 49.6 & 47.5 & 50.7 & 49.3 \\
\hline 64 & 415 & 580 & 32 & 220 & 195 & 214 & 57.9 & 56.1 & 58.5 & 57.5 \\
\hline 64 & 410 & 575 & 30 & 197 & 184 & 196 & 53.8 & 52.0 & 55.2 & 53.7 \\
\hline
\end{tabular}


From the above table, it can be seen that through a series of processes improvement, the conventional mechanical properties of these two thicknesses plates met the requirements of $\mathrm{Q} 370 \mathrm{qE}$ plate; moreover, the single values and the average values of the $Z$-direction performances were all above $45 \%$, fully met the requirements of Q370qEZ35, and thus achieved a very significant effect.

\section{CONCLUSIONS}

1) The disqualified $Z$-direction performance of the Q370qEZ35 heavy steel plate was mainly due to the presence of a large number of massive and strip-like $(\mathrm{Nb}$, $\mathrm{Ti}) \mathrm{C}$ and metal $\mathrm{Nb}$ inclusions as well as spherical oxide and sulfide inclusions, which destroyed the continuity of the steel substrate, caused the internal microstructures inhomogeneity, and finally resulted in the reduce of the Zdirection performance.

2) Through the rational optimization of the smelting, casting, rolling and colling processes, the Z-direction performances of the heavy plates were efficiently improved, and all the performance parameters met the requirements of technical delivery conditions.

\section{REFERENCES}

[1] B. L. Chen, "State of the art of the welded bridges in China," Electric Welding Machine, vol. 37, pp. 1-5, March 2007.

[2] Z. Y. Wang, "Application situation and development of Chinese bridges steel structure," Construction Technology, vol. 39, pp. 1-5, August 2010.

[3] W. J. Peng, H. H. Luo, H. Xue, and R. Ge, "Research on the veryhigh-cycle fatigue behavior of bridge steel," Metallurgical Analysis, vol. 34, pp. 284-287, October 2014.

[4] S. C. Zhu, "Analysis on the cause for disqualification of Zdirection property and control measures," Steelmaking, vol. 27, pp. 30-34, October 2011.

[5] H. D. Chen and D. S. Liu, "Industrial run to produce TMCP processed Q500qENH weathering heavy plate for bridge," Iron and Steel, vol. 49, pp. 69-75, April 2014.

[6] X. Z. Zheng, "Research and Development of Lamellar Tearing Resistant Heavy Plate," Shandong Metallurgy, vol. 30, pp.39-41, April 2008.

[7] A. N. Yang, Z. G. Li, and S. K. Ji, "Research and Analysis of Inclusions with Unqualified Z-direction Properties of Heavy Plates," Baosteel Technology, vol. 2, pp. 13-17,.

[8] S. C. Zhu, "Analysis of Disqualified z-Direction Properties of $120 \mathrm{~mm}$ Q390GJC-Z35 Steel," Journal of Iron and Steel Research, vol. 24, pp. 25-30, January 2012.

[9] T. Hiroshi, J. Y. Fu, and C. J. Shang, How to improve the performance of niobium steel-niobium steel production technology. Beijing: Chemical Industry Press, 2007.

[10] C. H. Zhang, F. C. Zhao, H. L. Sun, and J. B. Li, "Study on Layered Fracture of Ship Plate with Nb During Tensile Test," Material \& Heat Treatment, vol. 39, pp. 54-56, June 2010. 